\title{
Female Arab EFL Students Learning Autonomously Beyond the Language Classroom
}

\author{
Mehtap Kocatepe ${ }^{1}$ \\ ${ }^{1}$ English and Writing Studies, Zayed University, Abu Dhabi, United Arab Emirates \\ Correspondence: Mehtap Kocatepe, English and Writing Studies, Zayed University, Abu Dhabi, United Arab \\ Emirates. Tel: 971-561-243184 E-mail: Mehtap.Kocatepe@zu.ac.ae
}

Received: March 8, 2017 Accepted: April 18, 2017 Online Published: April 19, 2017

doi: 10.5539/elt.v10n5p104 URL: http://doi.org/10.5539/elt.v10n5p104

\begin{abstract}
Benson's (2011a; 2011b) identification of out-of-class learning as constituted by contexts, resources, levels of formality and more and less intentional pedagogic outcomes was used as a framework to investigate a group of tertiary level female Emirati EFL students' autonomous out-of-class learning experiences. Data collected via a survey, learner journals and semi-structured interviews indicated that out-of-class use of English and out-of-class language learning played a significant role in the lives of students beyond the classroom. These students utilised naturally occurring material resources, in particular movies, television, the Internet and digital and print texts, with varying levels of pedagogic intentionality, in the privacy of homes and perceived such resources as conducive to facilitating language learning. Students created and utilised self-directed naturalistic learning opportunities more than self-instruction and naturalistic learning. The study found that exercising choice and being intrinsically motivated were integral to autonomous out-of-class learning. Discursive resources were influential in enabling or constraining recognition and utilisation of social resources in creating learning opportunities. The paper ends by giving recommendations to educators for creating effective support for autonomous out-of-class language learning.
\end{abstract}

Keywords: Arab language learners, autonomous language learning, out-of-class language learning, self-directed language learning

\section{Introduction}

The need for language learners to take control of their learning beyond the classroom is widely accepted as a prerequisite for successful language learning (Nunan, 1991). The proliferation of self-access centres in the 1990s was an important initial step towards conceptualizing language acquisition as occurring in spaces and times outside classrooms (Gardner \& Miller, 1999). First generation Web tools, such as emails and discussion boards, also helped to multiply and vary language learning spaces. Today, computer mediated networks and mobile technologies have created formal and informal spaces beyond classrooms for learners to access an array of potential learning resources at any time, any place (Cope \& Kalantzis, 2009). The ubiquitous nature of learning has made it especially important for educators to plan and design pedagogical support for out-of-class learning.

Despite the ubiquitous nature of learning today, learning within the classroom continues to be a predominant concern of educational research, with less studied and written on self-initiated language learning outside classroom contexts (Benson, 2011a). Malcolm (2004) argues that it is time for teachers/researchers "to find out exactly what learners do [beyond the classroom] and how they improve [their learning] through doing this" (p. 7). Indeed, gaining insights into the contexts in which learning occurs beyond the classroom can help to shed light on the cognitive processes and pedagogic activities that language learners engage in beyond the gaze of the teacher. Such research can contribute to the creation of educational practices that enhance the effectiveness of out-of-class learning. To this end, the present study investigates the autonomous out-of-class learning experiences of a group of Gulf Arab tertiary level EFL students.

\section{Literature Review}

\subsection{Autonomy}

The concept of autonomy, widely defined as "the capacity to take control of one's learning" (Benson, 2011b, p. 58), underpins the practice of out-of-class learning. Autonomy refers to one's capacity for volition in initiating 
and pursuing a self-determined agenda (Benson, 2011b; Littlewood, 1996). Language learners exercise autonomy by co-constructing meanings and identities as they participate in social contexts both inside and outside the classroom. Such learners are socially agentive actors (Toohey \& Norton, 2003) who are critically aware of available affordances and who can "seek culturally alternative paths to learning", reshaping and transforming what they perceive to be contextual constraints (Gao, 2007, p. 261).

A view of autonomy as a social capacity to act on one's world of learning is grounded in a social view of learning. Situated learning theory posits that language is a social practice and that learning is the "process of being active participants in the practices of social communities and constructing identities in relation to these communities" (Wenger, 1998, p. 4). Language development involves the improvised practice of new meanings, practices and identities which are constructed and negotiated in the processes of social relations (Gee, 2004; Wenger, 1998). Whether learners are alone or with others, both inside and outside the classroom, learning occurs in and through participation in sociocultural practices (Lantolf, 2013). Lave and Wenger (1991) capture the conception that social contexts are the settings for learning with the term communities of practice. Communities of practice refer to groups of individuals who share cultural practices that reflect collective learning (Wenger, 1998). Communities establish coherent spaces through mutual engagement in a joint enterprise drawing on a shared repertoire of communal resources. Lave and Wenger (1991) coin the term legitimate peripheral participation to describe the process by which learners transform from novice members of a community of practice to becoming a full participant. Peripherality in participation suggests that learners can participate in multiple, diverse and more, or less, engaged ways in a community.

Autonomous learning, like learning itself, "emerges from the individual's participation in social practices distributed across numerous overlapping communities" (Lamb, 2013, p. 44). In their struggles to participate effectively in the web of power relations inherent in any learning context, language learners negotiate, adopt and/or contest the meanings, identities and discourses that are made available. They adopt a particular stance from which they take strategic action for their learning (Benson 2011; Breen \& Mann, 1997), a stance with which they evaluate and shape the contexts in which they are learning and create desirable learner identities. Such learners demonstrate a capacity for autonomous learning behaviour as they create and govern their worlds of learning.

It should be noted that autonomous out-of-class learning occurs when a language learner willingly enacts and fully endorses the action in which she or he is engaged (Chirkov, Ryan, Kim, \& Kaplan, 2003). Language learners who feel compelled to carry out a particular task or those who perceive their actions as being controlled by others (such as teachers or parents) might perform an out-of-class activity, but do so lacking autonomy. The focus of the present research was to examine instances of autonomous out-of-class learning practices where there is a sense of volition and agency, as it is such out-of-class activities that have the potential to facilitate learning and enhance personal and academic growth (Deci, Vallerand, Pelletier, \& Ryan, 1991).

\subsection{Out-of-class Learning}

Benson (2011a; 2011b) identifies a number of elements that constitute out-of-class learning: Context refers to the setting or location in which out-of-class learning occurs, and the activities and relationships that characterise that particular setting. Contexts are constituted by physical or virtual spaces as well as the social interactions that give them meaning. Any given context can provide opportunities for the use of a range of resources. Material resources refer to the tangible, physical elements of a context; social resources include networks of individuals or communities; discursive resources refer to the socially and culturally accepted norms and assumptions of what constitutes legitimate behaviour (Palfreyman, 2014). All of these resources can facilitate or limit the way a learner meets their learning goals. Menezes (2011) points out that not all learners will perceive the same resource as providing affordances for learning out-of-class. The activities that learners participate in as they make use of these resources are influenced by varying levels of formality. Benson uses the term formal to refer to resources that are aligned with institutional structures and curricular goals; the term informal is used to indicate that resources are not tied to institutional goals but rather occur naturally in everyday life. I will avoid using either of these terms in my discussion of the formality of resources as the terms evoke conceptions of informal resources being unstructured and ad hoc and formal resources being assigned official status. As a number of researchers have shown, naturally occurring resources, such as computer-mediated networks (Gao, 2007), video games (Ou, 2012) and popular culture (Sandlin, Wright, \& Clark, 2011), are equally structured and rigorous in terms of creating opportunities to learn. I will use the term curriculum-oriented to refer to resources that are aligned to classroom and/or curricular goals and naturally occurring in reference to contexts and resources that are available in everyday situations outside the classroom. 
Another element that constitutes out-of-class learning is the teaching and learning processes that are involved in learners' out-of-class learning experiences. Benson (2011b) situates pedagogic processes on a continuum ranging from the extent to which learning is a more, or less, intentional outcome of the activity. Self-instruction refers to the deliberate, self-initiated efforts of a learner to utilise existing resources to achieve a learning goal. An example of this is a learner writing down the lyrics of a song she listens to with the specific goal of improving spelling. Learners who take up self-instruction employ reflexivity and intentionality for the realisation of their own learning needs (Sealey \& Carter, 2004). Self-directed naturalistic learning is a less structured intentional learning experience. Here the learner uses naturally occurring contexts and resources to meet the dual purpose of fulfilling real-life needs, while at the same time recognising potential pedagogic gains of this activity. An example of self-directed naturalistic learning is a learner listening to a song with the intention of developing lexical repertoire. While listening to the song though, she does not engage in a specific language learning activity but is interested in the lyrics, the music and in enjoying the experience. The learner's engagement with the activity is motivated by an identification with and acceptance of the value of the activity and the perceived accompanying learning outcome (Deci et.al., 1991). At the other end of the continuum, naturalistic language learning involves learners' participation in real life situations to fulfil real life outcomes. For example, when a language learner listens to a song because she enjoys that particular type of music, the learner's primary purpose is to successfully making sense of the lyrics. She does not have a particular learning agenda to follow. Language development occurs as the learner participates in the meaning making processes underpinning the song.

From a view of learning as situated practice, all three forms of pedagogic processes can facilitate learning by providing opportunities for participation in social practices. As language learners move along a continuum of intentionality and awareness in realising learning needs, they participate in the symbolically mediated world of a foreign language (Pavlenko \& Lantolf, 2000). The various resources they interact with scaffold the language forms and functions that learners draw on as they negotiate and improvise meanings (Lantolf, 2000). Language learning is realised when learners appropriate the language of the social practice to co-construct new language knowledge (Pavlenko \& Lantolf, 2000).

\subsection{Research on Autonomous Out-of-class Learning}

In one of the earliest studies on the out-of-class learning experiences of EFL learners, Pickard (1996) reported that the German EFL learners in his study engaged predominantly in reading newspapers and novels and listening to the news. Pickard describes these learners as showing initiative and control over their learning environment. These learners' decisions to engage in receptive-skills based activities were based on a critical awareness of the resources that their particular EFL contexts made available to them.

Hyland (2004) and Chan (2011) found that tertiary level EFL Hong Kong learners engaged in listening and reading based activities out-of-class, such as watching movies, listening to songs and reading academic texts, and avoided speaking in English in public spaces. These learners displayed control of self-determined learning agendas beyond the classroom as they chose to engage in activities that served to both facilitate their learning and helped to create favourable social identities.

In another EFL context, Gao $(2007 ; 2009)$ identified online forums as providing out-of-class supportive learning spaces to Chinese EFL learners. He explains that participation in these spaces exemplified a willingness to learn and enhanced learners' levels of self-confidence, making them more expressive and more assertive than usual. Reporting on learners of English and Swedish in Finland, Kalaja, Alanen, Palviainen, and Dufva (2011) found that these learners utilised their immediate contexts to create learning opportunities beyond the classroom. While learners of English engaged in face to face interactions with speakers of English in Finland, the learners of Swedish made use of one particular resource which was readily available in Finland, that of product packages and labels in Swedish.

In the Gulf Arab context, Malcolm (2004) found that the Bahraini EFL students in her study fully endorsed the pedagogic benefits of watching movies and television and of speaking to native speakers. Malcolm describes these students as displaying willingness and confidence to learn beyond the classroom. Palfreyman's (2006) research on tertiary level female Emirati EFL learners shows how these learners also favoured utilising entertainment and communication related online resources for out-of-class learning purposes. In another study, Palfreyman (2011) writes about how the family functions as both an enabling and constraining learning resource for female Emirati EFL learners. Families' take up of social discourses of gender roles and relationships either opened up opportunities for learning beyond the classroom or restricted such access. While these studies do shed light on the ways Arab language learners were in charge of their language development out-of-class and how contexts shaped out-of-class language learning experiences, they did not examine what exactly students did with 
these activities to gain pedagogic outcomes.

A number of studies on autonomous out-of-class learning have adopted narrow conceptions of autonomy and, therefore, present limited findings. For example, Lai, Zhu, and Gong (2014) describe the Chinese EFL students in their study as lacking control over out-of-class learning practices because they relied on institutional materials for out-of-class learning and on the guidance of their parents and teachers. Similarly, Inozu, Sahinkarakas, and Yumru (2010) describe the Turkish EFL students in their study as unable to take responsibility for out-of-class learning because of their identification of teachers and friends as providing direction for out-of-class learning experiences. A limitation of both of these studies is that autonomous out-of-class learning is associated with individualised, isolated learning behaviour, and with independence from teachers, institutions and resources. These studies fail to recognise that autonomous actions can involve dependence on others who are perceived as providing support and guidance (La Guardia, Ryan, Couchman, \& Deci, 2000).

In an attempt to situate autonomous out-of-class learning in context, a number of studies take an ethnocentric view and blame learners' cultural backgrounds for what they perceive to be a lack of control of out-of-class learning. Al Asmari (2013) reports that in a Saudi Arabian EFL context, teachers were reluctant to provide support for autonomous out-of-class learning as they feared such behaviour would go against social and political discourses. Arab (Al-Khasawneh, 2010), Iranian (Afshar, Rahimi, \& Rahimi, 2014) and Malaysian (Ming \& Alias, 2007) students are reported as lacking autonomy in out-of-class learning because their cultural backgrounds are seen as incompatible with the exercise of autonomous learning behaviour. These researchers assume that culture itself, as if it is a monolithic, singular entity, is a constraining force. With the increasing number of international students studying in universities across the globe (UNESCO Institute for Statistics, 2014), it is becoming ever more important to abandon mass generalisations about cultural groups and instead to investigate the intricate connections between language learners and broader societal structures.

The present research seeks to address two gaps in the literature. First, it aims to provide insights into the complexity of out-of-class learning by investigating: a) the contexts in which language learners engage in out-of-class, b) the levels of formality of the activities they participate in, c) the resources learners draw on, and d) the pedagogic intentions of learners when participating in out-of-class learning contexts. A focus on all four elements of out-of-class learning in relation to autonomous language learning practices has been a neglected area of research. Secondly, the present study provides insights into the out-of-class learning practices of Gulf Arab language learners with the view that autonomous learning behaviour is not culture or context driven, but rather that it is contextually situated and socially mediated.

\section{The Study}

The goal of the present research was to explore the out-of-class learning practices that are endorsed and initiated by students, those that students exercised volition and self-determination in their engagement. Homework and other forms of imposed practices were not the focus of this research. Specifically, the research questions I sought to answer were:

1) How do students engage in naturalistic language learning beyond the classroom?

2) How do students engage in self-directed naturalistic language learning beyond the classroom?

3) How do students engage in self-instruction beyond the classroom?

\subsection{Research Context}

The research presented here took place in a gender segregated, English medium university in the United Arab Emirates. At the time of the study, I was teaching on the female student campus, hence the research involved only female students. These students were enrolled in an eight-week exit level course of an intensive English program, which I will refer to as the English Language Centre (ELC). The role of the ELC was to equip students with the required skills in and knowledge of English in order to attain an overall band of 5.0 in IELTS (International English Language Testing System), which was required for admission to the university's degree-granting programs. All of the students spoke Arabic as a home language and were Emirati nationals.

The United Arab Emirates (UAE) has an ethnically and linguistically diverse population. While Arabic is the official language of the country, Urdu, Hindi, Persian and Tagalog are used widely in everyday life (Library of Congress, 2007), and English is used as a lingua franca in most social interactions. Road signs, utility bills, public announcements, newspapers, television and radio programs are produced in both English and Arabic. The majority of taxi drivers, health care professionals, employees in the hospitality sector and a variety of other professionals in the country are capable of dealing with clients and customers in English. Tertiary education, media, tourism and international business are almost exclusively based on the use of English (Gallagher, 2011). 
It is quite possible, in fact, to live one's life in the UAE using solely English and without feeling any external pressure to learn or use Arabic.

Considering the widespread use of English in the UAE and the affluence of society, there appears to be in principle an abundance of real-time and virtual resources for language learners to access. The simple act of shopping in a mall, for instance, could provide a learner of English with opportunities for language development. Moreover, the affordability and widespread adoption of the most up-to-date telecommunications technologies can also, in theory, create contexts that afford ubiquitous language learning opportunities.

\subsection{Methodology}

A social constructionist paradigm underpins the present research in which language is perceived as a meditational tool for making sense of the world. Individuals do not discover knowledge but construct it by drawing on discourses and taking on identities available to them. Data were collected over eight weeks via a survey, learner journals and interviews. Table 1 below outlines the scheduling of each data collection tool:

Table 1. Scheduling of data collection tools

\begin{tabular}{|c|c|c|c|c|c|c|c|c|}
\hline & Week 1 & Week 2 & Week 3 & Week 4 & Week 5 & Week 6 & Week 7 & Week 8 \\
\hline Survey & $\checkmark$ & $\checkmark$ & & & & & & \\
\hline $\begin{array}{l}\text { Learner } \\
\text { journals }\end{array}$ & & & $\checkmark$ & $\checkmark$ & $\checkmark$ & $\checkmark$ & $\checkmark$ & \\
\hline Interviews & & & & & & $\checkmark$ & $\checkmark$ & $\checkmark$ \\
\hline
\end{tabular}

A ten-question survey adapted from Pearson (2003) and Hyland (2004) was administered in the first two weeks of the study. I piloted the survey the semester before the research was carried out with two groups of 15 students studying in the final semester of the ELC. I made changes to the survey based on their responses and suggestions. Appendix A lists the survey questions. I invited 123 students in eight exit level ELC classes to take part in the survey by an email in which I introduced myself and the research I planned to conduct. This email was forwarded to the students by their class teachers. I also visited each class in order to personalise the information in the email. The number of students who participated in the survey was 107.

I used the survey to investigate students' personal and academic backgrounds (questions 1 to 4 in Appendix A), the naturalistic and self-directed naturalistic learning activities they engage in beyond the university context (questions 5 and 6), the activities they engage in for self-instruction (questions 7 and 8) and the time students spend on out-of-class language learning (questions 9 and 10). In questions 5, 6, 7 and 8 students could choose an 'other' option, where they could add their own responses or comments to that particular question.

Students were also invited to keep a learner journal aimed at exploring the ubiquitous use of English outside the classroom and the potential learning opportunities that are available in students' lives. The journal instruction, therefore, asked students to record activities they engaged in out-of-class in English, without specific references made to language learning (see Appendix B). I emailed 123 students asking them to keep a weekly record of the activities they engaged in out-of-class in English by completing a seven question table in an MS Word document. Print outs of journal templates were given to class teachers to distribute to students. The journal entries were submitted anonymously to encourage students to feel confident in sharing their varying levels of engagement with English beyond the classroom without fear of being identified. To ensure anonymity, students were asked to leave completed journal entries in a box in the administrative assistant's office. At the end of the eight week study 23 anonymous journal entries were submitted. Of these 23 entries, seven described students' engagement with homework and, therefore, were irrelevant to the focus of the study. The other 16 entries described students' self-initiated and self-endorsed out-of-class engagement with English.

A third means of data collection were interviews. A total of 40 students volunteered to be interviewed, of which 28 showed up for the interviews. The interviews were conducted in my office on campus with individual students and in small groups of two or three students based on student preferences. The interview guide I developed was based on prompts and topics about out-of-class language learning, rather than specific questions (see Appendix C). The lack of specific wording of interview questions allowed me to have more flexibility in formulating questions and allowed for a more conversation-like interaction. The students appeared to be relaxed and eager to talk during the interviews. A total of approximately 550 minutes of interviews were recorded and 
transcribed. Each interviewee was given a copy of their interview to allow them to make additions or clarifications.

The data collected from journal entries and interviews were analysed using the tools of discourse analysis (Gee, 1999; 2011). The assumption underpinning a discourse analysis approach is that individuals use language to create and re-create the worlds they live in. Language is not an innocent, neutral tool that simply reflects an already existing reality; rather it is laden with values and beliefs which construct and sanction particular realities (Gee, 1999; 2015). Gee (1999) identifies seven areas of reality that individuals construct through language. These are a) significance b) practices c) identities d) relationships e) politics f) connections and g) knowledge. Applying these seven elements to the particular interest of this study, each written and spoken data was analysed in terms of what it suggested about:

a) the significance of out-of-class learning

b) the out-of-class learning activities a student engaged in

c) the identities a student adopted and assigned to others as they engaged in these activites

d) the relationships that were constructed around these activities

e) the power relations that shaped out-of-class learning

f) the material and social connections that were produced or hindered by out-of-class learning

g) the knowledge and belief claims that underpinned out-of-class learning

Key words and phrases were identified in the data that matched one or more of these seven elements. These key words and phrases were then categorised as potential responses to one of the three research questions. The frequency of each utterance was also recorded to identify the most commonly reported out-of-class learning experience.

\section{Findings}

In this section I discuss the findings of the study: First, I respond to the three research questions I posed earlier, which were aimed at investigating the level of pedagogic intentionality students have when engaging with out-of-class learning resources and contexts. This is followed by a discussion of how the out-of-class resources that these students engaged with had the potential to provide opportunities for language development. Third, I present a conception of autonomy as involving power relations where students consented to and at the same time contested discursive resources that constrained their personal lives. Next, I examine the role that choice played in students' recognition and utilisation of out-of-class learning opportunities. Finally, I discuss the implications of this study for language educators.

In my discussions of the findings I present excerpts from data. I have made no grammatical or lexical changes to student produced texts, except in cases where spelling mistakes were made in written data. Excerpts from data are given in single quotation marks. When necessary, I have included a correction or my own comment in square brackets. The names of students given are pseudonyms.

\subsection{Resources, Contexts, Formality and Pedagogy in Learning beyond the Classroom}

Out-of-class language learning played a significant role in the lives of this particular group of female Emirati EFL learners. According to survey results, more than $90 \%$ of respondents reported actively seeking opportunities to learn English beyond the classroom with 57\% claiming that out-of-class learning took up as much as one to two hours of every day. The majority of survey takers claimed frequent engagement with out-of-class learning with $20 \%$ choosing "usually" and $46 \%$ indicating "sometimes" in response to how often they engaged with out-of-class learning activities. In the interviews, each of the 28 interviewees was able and eager to draw on and discuss personal experiences of learning English out-of-class. The 16 journal entries that were relevant to the goals of this particular study also included specific details and examples as well as students' explanations of the contexts in which they engaged with out-of-class learning, the material and social resources they utilised and levels of formality of these resources.

Data suggested that engagement with out-of-class learning occurred almost exclusively within students' home contexts. Naturally occurring material resources were predominant in students' lives beyond the classroom in satisfying intrinsic interest as well as fulfilling pedagogic goals. In particular, watching television and movies, reading online and print texts and using the Internet were identified in all three forms of data collection as popular out-of-class learning resources. Curriculum-oriented material and social resources were both perceived as providing learning opportunities, but it was only the latter that was seen as providing personal satisfaction to 
students. Social interactions in English with members of the wider UAE community were not perceived as being desirable or as creating learning opportunities. Students' engagement with and use of resources is explained further below in relation to their level of pedagogic intentionality.

\subsubsection{Self-directed Naturalistic Language Learning}

The most commonly identified reason for engaging with a resource in English beyond the classroom was in order to fulfil both a real life, personally relevant goal and to attain learning gains. Ten of the 16 journal entries included references to watching movies and television in English or with English subtitles as 'fun' and 'enjoyable' and as contributing to language development. For example, one entry commented that watching movies was 'good because you can listen and speak. I think my vocabulary is bigger now and also I am speaking more easy because I can pronounce words. My grammar is also improving' (journal entry \#2). The role of movies and television in improving pronunciation and listening skills and in contributing to 'learning English in fun way' (journal entry \#7) was also echoed in 12 interviews. Amna, for example, said:

'I really love American movies ... I just watch because I learn a lot of vocab and speaking by movies. Movies improve our listening and speaking. We learn how to pronunciation.'

News programs and documentaries on television in English were associated with learning 'new and difficult vocabulary' (Muneera interview) and 'study[ing] grammar and pronunciation' (Zainab interview). Shaikha discussed how her interest in watching Korean drama and reading English subtitles helped to improve her speaking and writing abilities, in particular developing fluency in constructing sentences:

'I watch a lot of Korean series and I learned a lot of good vocabulary because I am reading subtitles. Maybe it is not very academic but I can speak and write pretty good now. Like I start the sentence correctly and I don't use Arabic words in my sentences.'

For some students, movies and television were seen as more desirable in motivating learning and facilitating language development than classroom-based academic study. Nour explained: 'I like watching movies, especially like Hollywood stuff. I watch maybe 3 series every night. I don't like homework or studying because I know that watching movies made my accent and my speaking way better'. An anonymous comment made in response to question 7 of the survey reiterated the same idea: ' $i$ can't study english coz $i$ find it boring so $i$ try to improve my english by doing things i like such as using twitter, watching movies, listening to music...etc.'

The Internet was also used for self-directed naturalistic language learning. Muna elaborated how her use of YouTube facilitated language proficiency:

'Actually my brothers always watch YouTube. But they watch cars and things like that. And also they are very good in English. So I asked them. I really struggled in English. I said I can understand but I can't speak. I can write but I can't speak. I asked them. They told me just listen and watch YouTube. Speak what they speak. What they do. I started to listen to English people speaking on YouTube. I started following channels that interested me. I think that helped me a lot with listening, in how to say a full word or a full sentence. Now I started to create my own channels. I have followers now...Last week I uploaded my slides from my presentation. ... Now I know how to create a full sentence, how to speak. In class I don't heard a conversation. Just reading and writing. Limited speaking in class.'

Muna believed that active participation in digital spaces contributed to language learning. She described how she progressed from being a consumer of information on the web to producing and disseminating information. Shamma too discussed her participation in digital contexts and the effects of this on her language learning. She explained that she wrote short stories in English, which she then published on a website:

'I comment on people's stories. I know many people on this website. I upload my stories and they comment on my story. Is it good? What did they like? This is important for me. So I can improve and write better.'

Shamma perceived participation in this website as contributing to the development of her identity as both a writer and a language learner. In this virtual space, she engaged in the mutual enterprise of creating fiction and negotiating understandings of this practice with others who were mutually engaged.

The Internet also provided opportunities for reading. Muna discussed her preference to engage in focused, goal-oriented online reading activities:

'I read English blogs about people travelling around the world. When we [her family] travel, before we travel, I read blogs about that country. It's good because I learn about the food, about the people, the place. I learned many new vocabularies with this way.'

Asma engaged in random Internet searches and believed that this provided learning opportunities. She said: 
'At home I open my laptop and start reading ...I read anything on the web. How to Photoshop. Something about movies. Me and my sister, we sit together and read and learn many new informations and vocabularies. If I'm bored I just search for things, anything...I read and I check vocabulary and I try to understand it. .... I think it's easy to read on my laptop. I can check anything I want, vocabulary, pronunciation. ...yes, it helped my English a lot. I couldn't speak in high school. Now I can.'

Asma utilised the wealth of information available on the Internet to contribute to the development of her lexical repertoire. She was aware of the dominance of English in the digital world and referred to the multitude of texts she could access in English. She perceived navigation between different webpages as effortless, which she believed contributed to her progress in learning at university. Many of the students who claimed to engage in self-directed naturalistic learning out-of-class believed that participation win the activity naturally led to language development; Amal explained: 'I just learn new vocabularies. It just happens.'

A smaller number of students (seven journal entries and three interviews) referred to students' engagement with curriculum-oriented social resources, in particular teachers and family members to fulfil personal and academic needs. For example, English was used with university teachers during office hours, with private tutors at home and was used to help younger siblings with homework. These interactions were believed to facilitate learning (It's good for speaking practice, journal entry \#1) and were seen as being enjoyable ('It's a fun way to teach and learn vocabulary', journal entry \#8).

\subsubsection{Self-instruction}

For seven interviewees, movies and television were popular resources to also engage in self-instruction. Ayesha, for example, explained that the genre of film, its storyline or the actors were of little relevance; rather what mattered was the pedagogic use of the movie. As she watched American or British movies, Ayesha would say words out loud to herself in an attempt to reproduce sounds accurately. Hajar too referred to watching movies with the primary intention of improving pronunciation:

'After dinner I sit with my parents. We watch [name of BBC TV drama]. I think my English became more better than last year... When I watch movies I want to imitate them. I sometimes talk to my friends like that too. Like I am American or something. It feels nice.'

Hajar added that she didn't mind which movie or television program she watched because all served the purpose of providing her with opportunities to reproduce the accents she heard, which she believed improved her pronunciation. Hajar appeared to believe that having a native speaker accent is key to language learning. Another student who used movies for self-instruction was Maryam who explained that she repeatedly paused a movie while watching it so as to mimic the pronunciation of words. Like Ayesha and Hajar, Maryam was interested in deciphering the string of sounds produced on screen and in replicating these, rather than the actual movie itself. She said:

'I watch American or Irish or anything, any movie. Sometimes I cannot remember it [the storyline] because I am stopping and stopping. But I remember the vocabularies...I am not American. I cannot talk like American really. It's not important really. But I can talk clearly and everyone can understand.'

Maryam did not simply regurgitate the sounds she heard in an attempt to mimic a foreign accent. Instead, she appropriated the sounds, making them fit in with her existing sound system. Improving pronunciation in order to engage in effective communication is what appears to drive Maryam to utilise movies for self-instruction.

In addition to developing fluency and accuracy in pronunciation skills, movies were also identified as enabling self-instruction in vocabulary development. Marwa explained how she used movies to develop her lexical repertoire: 'I watch [US television program] first without subtitles. Then I watch it with subtitles and try to match words and subtitles. I learn hard words.' Huda echoed Marwa's strategy of using subtitles to learn new vocabulary when she said:

'Just to challenge myself I cover the subtitles and figure out if I understand or not. I gained a lot of vocabulary by watching. They wouldn't teach you everything at school so you have to make an effort. So I listen more and watch more. You can pick up phrases and expressions just by watching. It's easier to form sentences.'

Both students used subtitles to monitor and expand their growth in vocabulary development. Huda's comment also suggests that she believed in exercising agency in taking charge of one's own learning.

A second resource that students identified as providing opportunities for self-instruction was using curriculum-oriented material resources. Five journal entries and three interviewees discussed their engagement with Blackboard Learn and educational websites for the purpose of revision for exams. Shamma, for example, 
explained how she took initiative in utilising resources shared by the class teacher to study for an exam. She said 'my teacher showed us BBC website and it's very useful for vocabulary. Every time before exams I studied from this website for vocabulary and I was getting good grades.' While educational goals were identified, students described the activities as 'necessary but boring' (journal \#10) and as 'not interesting but we have to do it' (Shaikha, interview).

It appeared that while both television and movies, and curriculum-oriented material resources are perceived as providing learning affordances, the former is intrinsically enjoyed while the latter is associated with motives external to the student herself, that of passing exams and attaining high grades. Students self-endorsed the activity of watching movies and television; they identified with and valued the outcome of the behaviour, thereby displaying a higher degree of self-determination (Ryan and Deci 2000b). These students also displayed more agency in transforming the particular resource into one that afforded learning opportunities. They self-designed and employed various strategies that helped them reach pre-determined pedagogic goals. On the other hand, the students who made use of curriculum-oriented resources assumed that participation in the activity itself and exposure to the language structures presented, which were aligned with classroom learning, would automatically lead to language development.

\subsubsection{Naturalistic Language Learning}

Resources for naturalistic language learning abounded in the lives beyond the classroom of seven interviewees and in four journal entries, but were not necessarily recognised as learning opportunities by students themselves. For example, Fatima described how watching and discussing Korean films was a jointly pursued interest for her circle of friends:

'I watch Korean drama but with English subtitles...During break time my friends, we sit together and I explain the story and they check and if I am wrong they correct my mistakes. Sometimes I understand something but really something very very different happened. Sometimes we sit on my laptop; we watch half of the movie; we talk and talk and cannot finish the movie in break time.'

Fatima and her friends engaged in this activity because of genuine enjoyment and mutual interest. Indeed, Fatima herself did not associate the activity with any learning gains. From her description of the activity though it is evident that these students' interactions involved confirmation and/or clarification of meanings made from the English subtitles, which indicates that they were engaged in deconstructing and reconstructing their understandings of written English text.

Shamma described how she checked the meanings of unknown words as she watched a movie. She said 'When I watch a movie or series, I see a difficult word so I Google translate it so I understand the word and keep it on my mind....I do this all the time.' She did not see this as constituting learning opportunities for her though. It was a natural part of watching movies. Sara and Amna also explained how they had to translate from English to Arabic while watching movies with family members. As English speaking members of the family, Sara and Amna were expected to engage in simultaneous translation to provide linguistic support to non-English speaking members of the family. This was not perceived to be a burden though. Indeed, it was their way of contributing to family unity and harmony. Wedad explained 'too many vocabularies in movie and I don't understand. But it's easy. I just check google and help my family enjoy and understand.'

Reading graded readers and novels was also referred to in three interviews and two journal entries as an activity some students enjoyed doing. Amna said that she read while spending time with her family members: 'I take my book and I sit with my family.' She recognised the pedagogic impacts of reading only when probed in the interview to specifically reflect on potential learning gains. Moza too described her passion for reading and reflected on possible learning gains only during the interview:

'I always read English books. Novels. I love novels. I even talk with Mrs Joanna [her ELC teacher]...She tells me the good books, books I should buy. At home I sit with my nephew and niece. And I read. Sometimes I read children's books with them. ..... Oh yeah maybe. Actually yes my pronunciation and vocabulary is good because I like reading.'

Explaining the use of naturalistic learning proved to be difficult for many of the students as in these contexts students achieve real-life outcomes rather than reach a pre-defined learning goal. They did not have an explicit pedagogic agenda in mind as they engaged in the activity. Indeed, as Tisdell and Thompson (2007) point out, entertainment media, such as television and movies, are engaged in for pleasure and to unwind, and viewers "don't constantly analyse or consciously think about the ways they are affected by it" (p. 668). It was only in hindsight that a few of the students realised the activity they engaged in could have helped to facilitate their 
language development. The naturalness of these activities in the lives of students or the discursive resources underpinning them had made the pedagogic implications less obvious to them.

A large number of references were made to the ubiquitous availability of social resources in students' lives beyond the classroom. Five journal entries and four interviewees described how they interacted in English with members of society, such as with employees in the hospitality sector, doctors and nurses, and the domestic employees who work for them (i.e. nannies, drivers and housekeepers). Interactions with these members of the expatriate UAE society were described as a necessity, required to fulfil communicative tasks in situations such as when 'you are sick' (journal entry \# 15) or 'hungry' (journal entry \# 1, 3, 9 and 12). These activities were perceived as an externally-regulated obligation due to the role of English as a lingua franca in the UAE. One journal entry explained that 'if he [the waiter] isn't speaking Arabic you must speak English' (journal entry \#1). In her interview Afra described how she had to translate for members of her family who did not speak English:

'In my family, my mother and husband's mother don't speak English. When they go to hospital and there is a foreigner I have to talk in English. Even in supermarkets, they put a Filipino or Indian. Sometimes they speak Arabic and English too but sometimes just English.'

Afra refers to the use of English in public spaces in the UAE as a requirement, rather than as a potential social resource for learning. She explained that such interactions did not provide her with enjoyment or personal satisfaction. These interactions were not self-endorsed.

Moreover, communication, in particular, with hospitality employees, nannies and drivers were perceived as not conducive to language learning. One journal entry explained 'In shopping malls the Filipino or Indian speak English but I don't feel like it's English speaker. English it is not first language of that people' (journal entry \#9). For other students, the non-native speaker status of nannies was seen as an obstacle to assisting others' language development:

Interviewer: So could this conversation with your nanny give you the chance to improve speaking skills or pronunciation?

Amna: No. No because she cannot speak English. She just saying some words about, just about my son and like that. She cannot talk like in good way.

It appears that students' views on their interactions with particular social resources were underpinned by discursive resources of local Emirati society that legitimise unequal power relations between members of the local population and the expatriate community. The potential out-of-class learning opportunities for these students were possibly constrained by students' own limited English proficiency, which made them feel less in charge of the interaction, as well as by the way they positioned interactions as valuable or not based on the socioeconomic and social status of the interlocutors.

\subsection{Learning as Participation in Social Practices beyond the Classroom}

With the data at hand, it is not possible to determine whether the resources and the strategies students utilised out-of-class actually had an impact on second language acquisition. The purpose of the study was not to document such changes, but rather to explore students' perspectives and experiences. What is evident from the data though is that, regardless of whether students were engaged in an activity for intentional self-instruction or unaware of potential learning outcomes, it was possible for language learning to occur as each resource provided opportunities to students to participate in social practices and to construct identities that allowed for effective co-participation and co-construction of knowledge (Wenger, 1998).

Diallo (2012) warns against the hegemonic presence of Western cultures and lifestyles in the lives of Muslim EFL learners. Indeed, movies, television programs and novels/stories allowed students to participate in the meaning making processes of various fictional non-Muslim/non-Arab worlds. Instances of cultural clashes were not mentioned in any of the data; in fact, it appears students perceived foreign popular culture as merely providing linguistic input which they could then internalise. However, if we assume that language is used to mediate our understanding of the world, then the Hollywood movies, North American novels and BBC programs these students were viewing certainly made available to them certain social practices that could have been interpreted as culturally and/or religiously inappropriate or contradictory. What is interesting is that Western-oriented popular culture was not the only resource students utilised. Korean, Japanese and Indian television and movies were also utilised. On blogs and websites, and on YouTube too, students engaged in the meaning making processes of individuals who were situated in a range of cultural, national, ethnic and religious contexts. Rather than creating uncertainty in the lives of these students, it seems that foreign resources expanded learners' opportunities to enhance language acquisition. These resources presented students with language and 
social practices that were "real, 'messy' and [were in contrast to] the tidier, more clinical language often met in the classroom" (Pinard, 2016, p. 135). Language learning occurred in these real and messy instances as students made sense of the familiar and the foreign by negotiating and adopting particular meanings while contesting others. Students participated in virtual and/or fictional worlds by improvising and appropriating semantic, linguistic and semiotic resources available to members of these communities.

Secondly, language learning could have occurred as students participated in various communities of practice. Fatima and her friends who watched Korean movies with subtitles, for example, constituted a community of practice. They were mutually engaged in a joint endeavour, which was to understand the content of a movie through the English subtitles provided. They shared a common repertoire of names of Korean movies, actors, and anticipated roles and plots associated with Korean drama. Their passion for watching Korean movies created a genuine interest and investment in using English. Muna who was an avid YouTube follower and created her own channels, and Shamma who posted her short stories on a writers' website were members of two different online communities of practice. These students communicated and negotiated meanings with group members drawing on and at the same producing resources, tools and discourses familiar to the community. They appropriated and improvised the linguistic and social practices of other members to develop competence in using English. Language learning occurred as these students struggled for meaningful participation in these online/fictional landscapes, as they became active participants in the practices of these social communities (Lave \& Wenger, 1991). In these spaces students navigated between their identities as novice language learners and alternative identities as writers of fiction, creators of YouTube channels and expert of Korean drama. Their membership in these communities not only provided a sense of belonging but also gave them public visibility as creators of content, as experts in their own right.

One might argue that merely watching a television program or reading a book alone would not entail social interaction. Indeed, while viewing a story unfold on a screen or in written text, one might be engaged in the activity alone, but we must remember that the individual, the event and the world mutually constitute each other (Lave \& Wenger, 1991). The viewer makes sense of the language and practices constructed on screen/in text by drawing on previous experiences and available worldviews, and re-constructs their own interpretation of language forms and functions that will help them pursue the trajectory of the storyline. A learner's interaction with a resource "may be overt, as in the case of social dialogue", such as when translating movie subtitles for other family members, or "it may be covert as in the case of private dialogue", such as when a student repeated a phoneme to herself (Lantolf, Thorne, \& Poehner, 2015, p. 214). In both cases, learners can test out their hypotheses of meanings they have created and co-construct meanings with participants of this fictional world in ways that may or may not be what was intended by the creators of the fiction.

Each resource students utilised provided them with exposure to input necessary for second language acquisition. When students engaged with resources, they were in charge of deciding on the difficulty of the linguistic input and making changes if they thought necessary. For example, if the lexical density of a movie or a blog proved to be too high, the student could move on to another movie or website. In this way, students could maintain an optimal level of linguistic difficulty in the spoken and written texts they engaged with. Moreover, many of these students adopted a multimodal approach to learning out-of-class. In movies and television programs, for example, they utilised both pictorial information, such as location and gestures, as well as spoken and written text (i.e. subtitles). Bisson, van Heuven, Conklin, and Tunney (2013) found that vocabulary acquisition and recall for language learners who adopted a multimodal method of learning was more rapid that those who didn't. Subtitles in English for English speaking movies and television programs have also been found to scaffold learning of new sounds and accent as subtitles can indicate which specific phonemes of words are being spoken and how they are pronounced (Mitterer \& McQueen 2009). Some students in this study believed that language learning occurred through repetition and imitation of sounds. For some, imitation involved a mere copying of sounds, and most probably did not result in learning; however, for a small group of students it does appear that they were repeating words and sounds in an attempt to appropriate the language form or sound. These students engaged in a creative process of re-constructing the word or sound and adding it to their existing repertoire of sounds to be drawn on in later interactions.

A great many resources that students engaged with were not associated with language gains; instead the activity itself is what motivated students. Indeed, some of them gave conscious thought to the practice and process of learning beyond the classroom for the first time in the interviews. Most of our naturally occurring interactions and engagement with resources occur in order to achieve a particular real-life goal. As Lantolf, Thorne, and Poehner (2015) point out, linguistic structures and functions are used as sub-goals in order help reach a higher real-life goal. For example, while watching a movie or reading a book, a language learner pays attention to the 
story and sequence of events. In order to make sense of these, however, the learner must also pay attention implicitly or explicitly - to the words and grammatical structures, to the pronunciation of words and their meanings in order to interpret and understand the unfolding of events. The specific subgoal of constructing meanings from given lexical and grammatical structures serves the higher goal of watching a movie or reading a novel. Whether the learner is conscious of this process or not, the learner is engaged in a goal-directed, meaningful activity. Wenger (1998) makes a similar observation in his argument that the reason why members of communities of practices do not perceive their engagement in the practice as learning is that "what they learn is their practice" (p. 95). Language serves the goal of mediating understandings and allows the individual to participate in the social practices that are relevant and meaningful to that particular community.

\subsection{Out-of-class Autonomy as a Social and Political Capacity}

Students' views on the out-of-class learning opportunities that social resources can potentially create were constrained by discursive resources of native speakerism and power relations within UAE society. Students did not appear to recognise the racist undertones of these discursive resources and lacked the agency to transform these constraints into opportunities. On the other hand, the same students demonstrated a much higher degree of agency and responded in more complex ways with regard to discursive resources that positioned themselves in undesirable ways and that presented constraints on their own personal lives. Such discourses were reshaped and transformed to more desirable experiences as students both supported and at the same time subverted the same discursive resource.

A pattern that emerged from the data about the contexts in which students interacted with material and/or social resources in English was that students' lives beyond the classroom were constrained to physical spaces within the home. 'When I finish classes I go home. Then I take a nap. Then I eat. After that I watch English series with my sisters' (Ameera, interview) was a typical description of students' out-of-class routines. In varying sequences, the activities of eating, napping, being involved in an activity of their choice, and spending time with family members were repeated in journal entries and by almost all of the interviewees. 'I sit with my family' was a commonly used phrase to express the idea that students participated in out-of-class activities while spending time with members of their family at home. For Emirati women, spending considerable amounts of time at home is natural as their daily life evolves around family social networks (Torstrick \& Faier, 2009). Emirati women are expected to hold on to rooted norms, prioritising family commitments and responsibilities, and at the same to embrace globalisation and modernity (Cooke, 2014). Many Emirati women today might be self-sufficient, but compared to Emirati men, they face far more restrictions on making decisions about their own lives (Ridge, 2011).

The students in this study demonstrated a capacity to "both resist and support the existing system of power" (Abu-Lughod, 1990, p. 47) that confined them to the home. They upheld cultural restrictions on their physical movement outside the house by adopting practices and identities that allowed for participation within the house. They supported and reinforced societal expectations of Emirati women to be nurturers and caregivers to family members by balancing their personal and academic needs while at the same time satisfying family expectations and social norms. For example, many of them integrated individualised activities, such as reading novels, into their family responsibilities and routines, and co-participated with other family members in screen-based activities. They endorsed traditional restrictions on face to face interaction between Emirati women and men by engaging in conversations only with friends, family (family members and domestic employees), teachers and tutors when alone (Bristol-Rhys, 2010). Interactions with male non-family members, such as doctors and waiters, occurred in the presence of other close family members. In this way, students took up familiar, comfortable identities that allowed them to participate effectively in Emirati society.

While conforming to this social norm, these students also challenged it as they participated in the social practices of movies and television and of novels, and as they interacted with members of the World Wide Web. The physical constraints of the home and restrictions on social interactions with members of the opposite gender were defied as students engaged in these fictional and/or virtual worlds. Movies and television, books and the Internet all created opportunities for the exploration of unfamiliar terrains "within the safe haven of a fictional world" (Geraghty, 2006, p. 251). These resources allowed students to experiment with the language and social practices of worlds that were remote and somewhat unreal. In such spaces students negotiated diverse worldviews, images and practices without fear of defying tradition or social norms. These students were moving in and out of new and old, familiar and foreign spaces and identities, creating for themselves comfortable, live-able third spaces that were constituted by elements of academia, personal interest as well as family life. Their identities as language learners and their roles as daughters/sisters/wives/mothers co-existed in these third spaces. The students in this study demonstrated a capacity to take charge of their lives out-of-class as they 
navigated between societal, familial and academic power networks and as they took on identities that allowed them to move in and out of being a language learner, a family member, an Emirati young woman and a global digital citizen.

\subsection{Exercising Choice in Out-of-class Learning}

Choice and intrinsic motivation played an integral role in students' initiation and pursuit of out-of-class learning opportunities. Patall and her colleagues' research (Patall, Cooper, \& Robinson, 2008; Patall, Cooper, \& Wynn, 2010) have demonstrated that providing students with choices in making decisions about the tasks they engage in enhances task performance, perceived competence and intrinsic motivation. Ryan and Deci (2000a) also argue that when an individual does not feel in control of her/his actions and outcomes, intrinsic motivation is diminished.

It is perhaps not surprising that students chose to engage with movies and television and the Internet as out-of-class learning resources. Recent figures from the UAE show that $71 \%$ of Emiratis, more than half of which are between 18 to 24 years old, reported watching movies in English with 53\% of them preferring to watch movies from the USA. $46 \%$ also reported that their favourite television program was in a language other than Arabic (Northwestern University in Qatar, 2016). Internet use in the UAE is also high with a penetration rate of 91\% (International Telecommunication Union, 2015). Students' choices to engage with reading as an intrinsically rewarding out-of-class activity is perhaps less obvious. The students in this study read popular novels, as well as graded readers, blogs and webpages for personal pleasure and satisfaction. These resources provided naturalistic and self-directed naturalistic learning opportunities. The identification of reading as playing a significant role in these students' lives beyond the classroom provides an alternative to the generalisation that Arab cultures lack reading habits (Gobert, 2009; Shannon, 2003). Arab students are often criticised for lacking an interest in written text and for being poor readers. In contrast to this stereotype, the students in this study displayed competence and confidence in reading texts of their own choice, which they perceived as an interesting and valuable activity.

Discursive resources also enabled and/or constrained choice and intrinsic motivation. Discourses of what it means to be a good language learner enabled engagement with curriculum-oriented material resources, such as Blackboard Learn and other course related online or print resources. These students associated learning with completion of worksheets and materials and revision of course material, and perceived successful language development as evidenced by attaining high grades in exams. While learning opportunities might have been created, these resources did not develop enthusiasm or personal investment to learn.

Secondly, discursive resources of social positioning enabled or constrained learning opportunities. Students' perceptions of the social status of interlocutors appeared to have limited their capacity to exercise their choices in creating out-of-class learning opportunities. To illustrate, the vast majority of teachers at the English Language Centre did not speak Arabic, so in actuality, students did not have the chance to choose the language they used with teachers. The only language they could use was English. This lack of choice in using Arabic or English with a teacher was not perceived by students as an imposition; quite the opposite, students interacted with teachers in English willingly and with great interest. On the other hand, a similar lack of choice in using Arabic with waiters and other hospitality employees was responded to with resentment. Using English in such interactions was seen as an imposition on students' themselves. It appears that it was acceptable for teachers, who are assigned authority and an expert, native speaker identity, to determine the language students would use out-of-class, but the same could not be expected of a waiter, who is perceived as holding a lower status in society. Students' apparent lack of recognition in the ways such discursive assumptions positioned some members of society as superior to others, and the ways it naturalised the view that knowledge and social status are directly correlational, presented constraints on their out-of-class learning.

Students' recognition of the ways they, as Emirati women, are positioned to adopt roles assigned to them by society and family, and to participate only in socially sanctioned practices, facilitated their exercise of choice and agency. They exercised choice in engaging in out-of-class learning by abiding by social norms of gender relationships and fulfilling family expectations; however, at the same time they transgressed these norms and roles by actively participating in fictional and/or virtual worlds where they had a choice to interact in practices and with individuals that might not be possible in their real worlds. Making such choices created a genuine interest in learning.

\section{Implications for Educators}

Findings from the present study suggest a number of implications for pedagogic practice. First, it is important for educators to recognise what students are already capable of doing beyond the classroom and to use these 
practices to create with students optimal conditions for learning outside the classroom (Smith, 2003). Language learners need to be made aware that out-of-class language development is not only constituted by participating in curriculum-based activities, but also by engaging with naturally occurring, everyday material and social resources. Ryan and Deci (2000a) argue that many of the tasks educators assign to students are not inherently interesting or enjoyable. Therefore, it is especially important to utilise and incorporate into teaching elements of students' out-of-class worlds which have personal significance and value. One way of doing this would be to assure language learners that popular culture, in particular movies, television, novels, YouTube and blogs, for example, are legitimate resources for engagement with a foreign language and for creating opportunities for language learning.

Language learners' interests in popular culture has been documented in research since Pickard's 1996 study of German EFL learners choosing to read newspapers and novels as a way to develop English out-of-class; however, in most higher education contexts around the world, language education curricula do not include a specific focus on such activities. In fact, the integration of popular culture into mainstream education has been quite a contentious issue. Popular culture has been dichotomised against formal education, with the former being used to refer to entertainment and triviality while the latter is associated with reason and objectivity; popular culture is often used to lessen the seriousness of formal education and is not seen as having pedagogic value itself (Benson, 2014). Benson and Chik (2014) point out that the pedagogic problem is that generational differences between educators and learners in terms of how popular culture is experienced leads educators to fail to see the educational value of popular culture from learners' perspectives. Moreover, some language educators have described the incorporation of learner interests into language pedagogy as edutainment and have warned that such a perspective gives learners the impression that learning should only and always be colourful and fun without serious work involved (Okan, 2003; Olson \& Clough, 2001). These researchers perceive such practices as jeopardising academic learning as learners are encouraged to focus on enjoyment, leading to inabilities to cope with academic challenges. However, the language learners in this study showed that they were not merely passive receivers of content, but were strategic in their utilisation of these activities and resources. The tools they employed to achieve pedagogic goals from an activity, such as covering subtitles, posting stories online or mimicking accents, were unique and effective. Whether it was producing texts for a YouTube channel for a global audience or comprehending and translating spoken/written texts on television screens for family members, these students were creating opportunities for personalised, meaningful learning. It is important for educators to fully utilise the role of intrinsically interesting activities as these help to raise student motivation and engagement in and out-of-class.

In an attempt to recognise and utilise learners' out-of-class learning experiences, some educators recommend providing language learners with teacher-designed tasks that guide them in how to access and utilise resources out-of-class. In relation to the use of YouTube, for example, Morrison and Navarro (2014) argue that teachers should model their use of YouTube to fulfil a language-related goal, rather than "just letting the learners assume that 'YouTube is good for listening"” (p. 60). Pellicer-Sánchez and Schmitt (2010) argue for the integration of teacher-designed materials in maximizing vocabulary gains made from reading novels beyond the classroom. They suggest using post-reading questions that can help consolidate comprehension of the text. While there is value in modelling and consolidating learning, a teacher-led inquiry into the use of YouTube or other element of learner interest would delimit learner choice and would underplay the skills and abilities learners are already equipped with. Introducing teacher interventions into out-of-class learning would also risk compromising the uniqueness of each learners' engagement with learning beyond the classroom and would fail to support naturalistic learning endeavours. Murray (2008) proposes that instead of teacher-intervention beyond the classroom, learners' out-of-class stories can be brought into the classroom. Learners can share with class members their out-of-class learning stories, the strategies and methods they employ to access and use resources. Each learner's out-of-class learning story would provide a provisional model of out-of-class learning, which would highlight the uniqueness of each learner's attempts at out-of-class language learning and would make different tools and strategies available to other learners. Another pedagogic practice that could assist in broadening language learners' access to learning opportunities is to introduce critical literacy in the classroom (Morgan, 1997). The analytical and linguistic toolkit espoused in critical literacy could help to make explicit to students how language is used in media to construct particular worldviews as normal and others as deviant; it would develop an awareness of power relations and how individuals are positioned in particular networks of power. Such a pedagogic approach could encourage reflection on students' own use of media and discourse out-of-class.

Another pedagogic implication of the study is for educators to move away from conceptions of tertiary level 
language learners as free-willed, independent, rational beings. Such a positivist conception often leads to disregarding the various ways adults are implicated in family and social structures. Instead, we need to reconceptualise language learners as socially, culturally situated individuals navigating through familiar and foreign spaces, meanings and identities. While some attention is paid in universities to providing emotional support to international students through, for example, homestay families, more explicit attention needs to be given to the various ways personal and social identities co-exist for some of these language learners. In the particular Gulf Arabian context of this study, despite globalisation and massive socio-economic changes in the country, the family and society remain at the crux of an individual's life and are the major motivators for learning (Engin \& McKeown, 2012; Palfreyman, 2006). This is not to suggest that students of Gulf Arab background are incapable of leading a life without family mediation or are unable to make decisions on their own. Rather, the implication here is that as language educators it is important for us to recognise and appreciate the connectedness of Emirati students to broader sociocultural contexts and the ways their activities are grounded in social values and assumptions. Such understandings can help in maximising learning opportunities and creating pedagogically supportive environments.

\section{Conclusion}

Benson's (2011a; 2011b) identification of out-of-class learning as constituted by contexts, resources, levels of formality and more and less intentional pedagogic outcomes was used as a framework to situate a group of tertiary level Emirati female EFL learners' autonomous out-of-class learning experiences. Data collected via a survey, learner journals and interviews indicated that choice and intrinsic motivation were integral to students' engagement with out-of-class learning. The majority of students expressed genuine interest and enjoyment in engaging with naturally occurring material resources, in particular with watching television and movies, using the Internet for audio/video resources and reading novels, graded readers, blogs and other digital texts. Many of them believed that engagement with these resources resulted in learning outcomes, and some discussed the specific, unique strategies they employed to transform an everyday resource into a learning affordance. Curriculum-oriented material resources were also utilised to assist language development but were not identified as intrinsically interesting. In terms of pedagogy, self-directed naturalistic learning was prevalent in students' lives with a dual focus on engaging with an activity for pleasure as well as with an anticipated learning outcome. Naturalistic learning opportunities were the least visible to students.

Discursive resources were influential in the recognition and utilisation of social resources in creating learning opportunities. Family members and teachers were assigned legitimacy in providing opportunities for language development. The social status of the former and the expert identity assigned to the latter group made them recognisable as resources for learning. Interactions with members of lower social and/or socioeconomic groups were not self-endorsed or self-determined. Instead, they were perceived as functional, communicative obligations imposed on them due to the role of English as a lingua franca. The adoption of discursive resources constraining students' personal lives was responded to in more complex ways. Students endorsed assumptions that assign Emirati women to domestic spaces and duties but at the same time were able to contest the physical confinement of the very same discourses. By engaging in fictional and/or virtual spaces and interacting with fictional and/or virtual individuals in 'other' spaces, students expanded their experiences of interacting with foreign meanings and understandings. They were able to negotiate foreign and familiar social practices and appropriate new meanings and understandings without leaving the privacy of their homes or defying their roles as nurturers and caretakers. They created for themselves worlds of learning in which they could socialise with engaged participants in activities that they valued and enjoyed. Autonomy in out-of-class learning was not a fixed attribute but any one student moved along a continuum of autonomous behaviour as they engaged with different discursive resources and adopted different identities, demonstrating more or less ownership of learning.

One limitation of the study is that it includes the voices of only female students. Secondly, the study re-constructs the experiences of only those students who volunteered to take part in the research. It is highly likely that these students were already engaged with and invested in out-of-class learning. Future research would benefit from investigating the perceptions and experiences of a more varied group of learners, such as different age groups, male students as well as those who claim to not engage in out-of-class learning and the reasons why they choose to do so. Research could also be conducted on the pedagogic impact of bringing out-of-class learning experiences into the classroom through provisional models of out-of-class learning.

\section{References}

Abu-Lughod, L. (1990). The romance of resistance: Tracing transformations of power through Bedouin women. American Ethnologist, 17(1), 41-55. https://doi.org/10.1525/ae.1990.17.1.02a00030 
Afshar, H. S., Rahimi, A., \& Rahimi, M. (2014). Instrumental motivation, critical thinking, autonomy and academic achievement of Iranian EFL learners. Issues in Educational Research, 24(3), 281-298.

Al Asmari, A. (2013). Practices and prospects of learner autonomy: Teachers' perceptions. English Language Teaching, 6(3), 1-10. https://doi.org/10.5539/elt.v6n3p1

Al-Khasawneh, F. M. S. (2010). Writing for academic purposes: Problems faced by Arab postgraduate students of the College of Business. ESP World, 2(28), 1-23.

Benson, P. (2011a). Language learning and teaching beyond the classroom: An introduction to the field. In P. Benson, \& H. Reinders (Eds.), Beyond the language classroom (pp. 7-16). Hampshire: Palgrave Macmillan. https://doi.org/10.1057/9780230306790_2

Benson, P. (2011b). Teaching and researching autonomy (2nd ed.). Harlow: Pearson Education.

Benson, P. (2014). Popular culture as education. How it teaches and how we learn. In P. Benson, \& A. Chik (Eds.), Popular culture, pedagogy and teacher education: International perspectives, (pp. 12-25). London: Routledge.

Benson, P., \& Chik, A. (2014). Popular culture in informal and formal education. In P. Benson, \& A. Chik (Eds.), Popular culture, pedagogy and teacher education: International perspectives, (pp. 1-8). London: Routledge.

Bisson, M. J., van Heuven, W. J. B., Conklin, K., \& Tunney, R. J. (2013). Incidental acquisition of foreign language vocabulary through brief multi-modal exposure. PLoS ONE, 8(4). https://doi.org/10.1371/journal.pone.0060912

Breen, M. P., \& Mann, S. J. (1997). Shooting arrows at the sun: Perspectives on a pedagogy for autonomy. In P. Benson, \& P. Voller (Eds.), Autonomy and independence in language learning, (pp. 132-149). New York: Addison Wesley Longman.

Bristol-Rhys, J. (2010). Emirati women: Generations of change. London: Hurst \& Company.

Chan, W. H. W. (2011). Learner autonomy and the out-of-class English learning of proficient students in Hong Kong. The International Journal of Learning, 17(11), 45-62.

Chirkov, V., Ryan, R. M., Kim, Y., \& Kaplan, U. (2003). Differentiating autonomy from individualism and independence: a self-determination theory perspective on internalization of cultural orientations and well-being. Journal of personality and social psychology, 84(1), 97-110. https://doi.org/10.1037/0022-3514.84.1.97

Cooke, M. (2014). Tribal Modern. Berkeley: University of California Press.

Cope, B., \& Kalantzis, M. (2009). Ubiquitous Learning. Urbana: University of Illinois Press.

Deci, E. L., Vallerand, R. J., Pelletier, L. G., \& Ryan, R. M (1991). Motivation and education: The self-determination perspective. Educational Psychologist, $26(3 \quad \& \quad 4), \quad 325-346$. https://doi.org/10.1080/00461520.1991.9653137

Diallo, I. (2012). Intercultural teaching in the Arab Gulf region: Making a case for paedagogy that takes into account the epistemic context and the scholastic traditions of Muslim students. Internatonal Journal of Pedagogies and Learning, 7(3), 211-217. https://doi.org/10.5172/ijpl.2012.7.3.211

Engin, M., \& McKeown, K. (2012). Cultural influences on motivational issues in students and their goals for studying at university. Learning and Teaching in Higher Education. Gulf Perspectives, 9(1), 1-15.

Gallagher, K. (2011). Bilingual education in the UAE: factors, variables and critical questions. Education, Business and Society, 4(1), 62-79. https://doi.org/10.1108/17537981111111274

Gao, X. (2007). A tale of Blue Rain Cafe: A study on the online narrative construction about a community of English learners on the Chinese mainland. System, 35(2), 259-270. https://doi.org/10.1016/j.system.2006.12.004

Gao, X. (2009). The 'English corner' as an out-of-class learning activity. ELT Journal, 63(1), 60-67. https://doi.org/10.1093/elt/ccn013

Gardner, D., \& Miller, L. (1999). Establishing self-access: From theory to practice. Cambridge: Cambridge University Press.

Gee, J. P. (1999). An introduction to discourse analysis. Theory and method. New York: Routledge. 
Gee, J. P. (2004). Situated language and learning. A critique of traditional schooling. New York: Routledge.

Gee, J. P. (2011). How to do discourse analysis. A toolkit. New York: Routledge.

Gee, J. P. (2015). Social linguistics and literacies: Ideology in Discourses. (5th ed.) New York: Routledge. https://doi.org/10.1075/ld.5.2.06gee

Geraghty, C. (2006). Soap opera and utopia. In J. Storey (Ed.), Cultural theory and popular culture: A reader (pp. 246-154). London: Pearson Prentice Hall.

Gobert, M. (2009). Key findings from research and implications for the classroom. In D. Anderson, \& M. McGuire (Eds.), Cultivating real readers (pp. 53-63). Abu Dhabi: HCT Press.

Hyland, F. (2004). Learning autonomously: Contextualising out-of-class English language learning. Language Awareness, 13(3), 180-202. https://doi.org/10.1080/09658410408667094

Inozu, J., Sahinkarakas, S., \& Yumru, H. (2010). The nature of language learning experiences beyond the classroom and its learning outcomes. US-China Foreign Language, 8(1), 14-21.

International Telecommunication Union (ITU). (2015). Percentage of individuals using the Internet. Retrieved from http://www.itu.int/en/ITU-D/Statistics/Pages/stat/default.aspx

Kalaja, P., Alanen, R., Palviainen, A., \& Dufva, H. (2011). From milk cartons to English roommates: Context and agency in L2 learning beyond the classroom. In P. Benson, \& H. Reinders (Eds.), Beyond the language classroom (pp. 47-58). Hampshire: Palgrave Macmillan. https://doi.org/10.1057/9780230306790_5

La Guardia, J. G., Ryan, R. M., Couchman, C. E., \& Deci, E. L. (2000). Within-person variation in security of attachment: a self-determination theory perspective on attachment, need fulfillment, and well-being. Journal of personality and social psychology, 79(3), 367-384. https://doi.org/10.1037/0022-3514.79.3.367

Lai, C., Zhu, W., \& Gong, G. (2014). Understanding the quality of out-of-class English learning. TESOL Quarterly, 1-31.

Lamb, M. (2013). The struggle to belong: Individual language learners in Situated Learing Theory. In P. Benson, \& L. Cooker (Eds.), The Applied Linguistic Individual (pp. 32-45). Sheffield: Equinox.

Lantolf, J. P. (2013). Sociocultural theory and the dialectics of L2 learner autonomy/agency. In P. Benson, \& L. Cooker (Eds.), The applied linguistic individual (pp. 16-31). Sheffield: Equinox.

Lantolf, J. P, Thorne, S. L., \& Poehner, M. E. (2015). Sociocultural theory and second language development. In B. vanPatten, \& J. Williams (Eds.), Theories in second language acquisition (pp. 207-226). Mahwah, NJ: Lawrence Erlbaum Associates.

Lave, J., \& Wenger, E. (1991). Situated learning: Legitimate peripheral participation. Cambridge: Cambridge University Press. https://doi.org/10.1017/CBO9780511815355

Library of Congress. (2007). Country profile: United Arab Emirates. Retrieved from http://lcweb2.loc.gov/frd/cs/profiles/UAE.pdf

Littlewood, W. (1996). "Autonomy": An anatomy and a framework. System, 24(4), 427-435. https://doi.org/10.1016/S0346-251X(96)00039-5

Malcolm, D. (2004, September). Investigating successful English learners in Arab medical schools. Paper presented at the Independent Learning Conference, Melbourne, Australia. Retrieved from http://www.independentlearning.org/uploads/100836/ila03_malcolm.pdf

Menezes, V. (2011). Affordances for language learning beyond the classroom. In P. Benson, \& H. Reinders (Eds.), Beyond the language classroom (pp. 59-71). London: Palgrave. https://doi.org/10.1057/9780230306790_6

Mitterer, H., \& McQueen, J. M. (2009). Foreign subtitles help but native-language subtitles harm foreign speech perception. PLoS ONE, 4(11), 77-85. https://doi.org/10.1371/journal.pone.0007785

Ming, T. S., \& Alias, A. (2007). Investigating readiness for autonomy: A comparison of Malaysian ESL undergraduates of three public universities. English Language Teaching, 6(1), 1-18.

Morgan, W. (1997). Critical literacy in the classroom: The art of the possible. London: Routledge. https://doi.org/10.4324/9780203282489

Morrison, B., \& Navarro, D. (2014). The autonomy approach: Language learning in the classroom and beyond. Surrey: Delta Publishing. 
Murray, G. (2008). Pop culture and language learning: Learners' stories informing EFL. Innovation in Language Learning and Teaching, 2(1), 2-17. https://doi.org/10.1080/17501220802158792

Northwestern University in Qatar. (2016). Media use in the Middle East 2016. A six nation survey. Doha Film Institute.

Retrieved

from http://www.qatar.northwestern.edu/docs/publications/research-media-use/2016-middle-east-media-use-repo rt.pdf

Nunan, D. (1991). Language Teaching Methodology. London: Prentice Hall.

Okan, Z. (2003). Edutainment: Is learning at risk? British Journal of Educational Technology, 34(3), 255-264. https://doi.org/10.1111/1467-8535.00325

Olson, J. K., \& Clough, M. P. (2001). Technology's tendency to undermine serious study: A cautionary note. The Clearing House, 75(1), 8-13. https://doi.org/10.1080/00098650109599225

Ou, L. (2012, August). Learning Japanese beyond the classroom with internet resources: A case study of a Japnese major university student in Mainland China. Paper presented at the 5th Independent Learning Association Conference, Wellington, New Zealand. Retrieved from https://www.independentlearning.org/uploads/100836/files/ILA_2012_Proceedings.pdf

Palfreyman, D. (2006). Social context and resources for language learning. System, 34, 352-370. https://doi.org/10.1016/j.system.2006.05.001

Palfreyman, D. (2011). Family, friends, and learning beyond the classroom: Social networks and social capital in language learning. In P. Benson, \& H. Reinders (Eds.), Beyond the language classroom (pp. 17-34). Hampshire: Palgrave Macmillan. https://doi.org/10.1057/9780230306790_3

Palfreyman, D. (2014). The ecology of learner autonomy. In G. Murray (Ed.), Social dimensions of autonomy in language learning (pp. 175-191). London: Palgrave Macmillan. https://doi.org/10.1057/9781137290243.0018

Patall, E. A., Cooper, H., \& Robinson, J. C. (2008). The effects of choice on intrinsic motivation and related outcomes: A meta-analysis of research findings. Psychological Bulletin, 134(2), 270-300. https://doi.org/10.1037/0033-2909.134.2.270

Patall, E. A., Cooper, H., \& Wynn, S. R. (2010). The effectiveness and relative importance of choice in the classroom. Journal of Educational Psychology, 102(4), 896-915. https://doi.org/10.1037/a0019545

Pavlenko, A., \& Lantolf, J. P. (2000). Second language learning as participation and the (re)construction of selves. In J. P. Lantolf (Ed.), Sociocultural Theory and Second Language Learning (pp. 155-177). Oxford: Oxford University Press.

Pearson, N. (2003, September). The idiosyncracies of out-of-class language learning: A study of mainland Chinese students studying English at tertiary level in New Zealand. Paper presented at the The Independent Learning Conference, Melbourne, Australia. Retrieved from https://www.independentlearning.org/uploads/100836/ila03_pearson.pdf

Pellicer-Sánchez, A., \& Schmitt, N. (2010). Incidental vocabulary acquisition from an authentic novel: Do Things Fall Apart? Reading in a Foreign Language, 22(1), 31-55.

Pennycook, A. (1997). Cultural alternatives and autonomy. In P. Benson, \& P. Voller (Eds.), Autonomy and independence in language learning (pp. 35-53). New York: Addison Wesley Longman.

Pickard, N. (1996). Out-of-class language learning strategies. ELT Journal, 50(2), 150-159. https://doi.org/10.1093/elt/50.2.150

Pinard, L. (2016). Looking outwards: using learning materials to help learners harness out-of-class learning opportunities. Innovation in Language Learning and Teaching 10(2), 133-143. https://doi.org/10.1080/17501229.2015.1090997

Ridge, N. (2011, April 14). Why women graduates outnumber men in the UAE. Gulf News, Retrieved from http://gulfnews.com/gn-focus/why-women-graduates-outnumber-men-in-the-uae-1.790849 .

Ryan, R. M., \& Deci, E. L. (2000a). Intrinsic and extrinsic motivations: Classic definitions and new directions. Contemporary Educational Psychology, 25, 54-67. https://doi.org/10.1006/ceps.1999.1020

Ryan, R. M., \& Deci, E. L. (2000b). Self-determination theory and the facilitation of intrinsic motivation, social $\begin{array}{llll}\text { development, and } \quad \text { American } & \text { Psychologist, }\end{array}$ 
https://doi.org/10.1037/0003-066X.55.1.68

Sandlin, J. A., Wright, R. R., \& Clark, C. (2011). Reexamining theories of adult learning and adult development through the lenses of public pedagogy. Adult Education Quarterly, 63(1), 3-23. https://doi.org/10.1177/0741713611415836

Shannon, J. (2003). Getting Gulf students to enjoy reading. Perspectives, 11(1), 21-24.

Smith, R. C. (2003). Pedagogy for autonomy as (becoming-) appropriate methodology. In D. Palfreyman, \& R. C. Smith (Eds.), Learner Autonomy Across Cultures: Language Education Perspectives (pp. 129-146). Hampshire: Palgrave Macmillan. https://doi.org/10.1057/9780230504684_8

Tisdell, E. J., \& Thompson, P. M. (2007). 'Seeing from a different angle': the role of pop culture in teaching for diversity and critical media literacy in adult education. International Journal of Lifelong Education, 26(6), 651-673. https://doi.org/10.1080/02601370701711349

Toohey, K., \& Norton, B. (2003). Learner autonomy as agency in sociocultural settings. In D. Palfreyman, \& R. C. Smith (Eds.), Learner autonomy across cultures: Language education perspectives (pp. 58-72). New York: Palgrave Macmillan. https://doi.org/10.1057/9780230504684_4

Torstrick, R. L., \& Faier, E. (2009). Culture and customs of the Arab Gulf States. Santa Barbara, CA: Greenwood Press.

UNESCO Institute for Statistics. (2014). Global flow of tertiary-level students. Retrieved from http://www.uis.unesco.org/Education/Pages/international-student-flow-viz.aspx

Wenger, E. (1998). Communities of practice: Learning, meaning and identity. Cambridge: Cambridge University Press. https://doi.org/10.1017/CBO9780511803932

\section{Appendix A}

\section{Out-of-class learning survey questions and results}

Dear students, I am researching the types of activities you do outside the classroom. My interest is in finding out about the activities you choose/want to do (that is, not those you are told to do by your teacher). If you would like to participate in this research, please complete this survey. In this survey, you will not be asked your name or any other type of personal information. Your identity in the survey will be anonymous (unknown). The survey will take between 5-10 minutes. Your participation is voluntary. If you decide not to participate, your decision will not affect your present or future relations with the university. Thank you.

1. Please choose your age group.

\begin{tabular}{lcc}
\hline & Response Total & Response Percent \\
\hline $17-22$ & 104 & $97 \%$ \\
$23-29$ & 3 & $3 \%$ \\
$30-35$ & 0 & $0 \%$ \\
36 and older & 0 & $0 \%$ \\
\hline
\end{tabular}

2. How long have you been learning English?

\begin{tabular}{lcc}
\hline & Response Total & Response Percent \\
\hline 0-2 years & 24 & $22 \%$ \\
$3-5$ years & 6 & $6 \%$ \\
$6-8$ years & 9 & $8 \%$ \\
9 years and more & 68 & $64 \%$ \\
\hline
\end{tabular}

3. Choose the sentence which best describes your view of your current level of English.

\begin{tabular}{lcc}
\hline & Response Total & Response Percent \\
\hline My English is weak and I need to improve it a lot. & 7 & $7 \%$ \\
My English is good but there are still some things I & 84 & $79 \%$ \\
\hline
\end{tabular}


need to learn.

I shouldn't be in the ABP. I don't need to improve my English.

16

0
$15 \%$

$0 \%$

4. Please choose whether you agree or disagree with each of the following statements.

\begin{tabular}{lcr}
\hline & Agree & Disagree \\
\hline $\begin{array}{l}\text { I use English a lot outside a classroom } \\
\text { setting. }\end{array}$ & $67.29 \%(72)$ & $32.71 \%(35)$ \\
$\begin{array}{l}\text { I feel comfortable when I use English in a } \\
\text { social setting. }\end{array}$ & $82.24 \%(88)$ & $17.76 \%(19)$ \\
I feel comfortable when I use English for \\
$\begin{array}{l}\text { academic purposes. } \\
\text { I look for opportunities to use and improve } \\
\text { my English in everyday life. }\end{array}$ \\
$\begin{array}{l}\text { I dislike using English. }\end{array}$
\end{tabular}

5. Choose the activities below that you do in English in your free time out-of-class. You can choose more than one. (Survey results are listed in descending order)

\begin{tabular}{lcc}
\hline & Response total & Response Percent \\
\hline Watch TV/films & 96 & $93 \%$ \\
Listen to songs & 81 & $79 \%$ \\
Listen to the radio & 26 & $25 \%$ \\
Read magazines/ newspapers & 45 & $44 \%$ \\
Read stories/novels & 64 & $62 \%$ \\
Keep a personal journal & 13 & $13 \%$ \\
Speak with friends & 56 & $54 \%$ \\
Speak with family members & 41 & $40 \%$ \\
Chat on smartphone apps & 60 & $58 \%$ \\
Attend meetings (e.g. student clubs) & 15 & $15 \%$ \\
Surf the Internet & 59 & $57 \%$ \\
Write on social networking sites (Facebook, twitter & 35 & $34 \%$ \\
etc.) & & $42 \%$ \\
Write emails & 43 & $16 \%$ \\
Play video games & 16 & $1 \%$ \\
Other: Write down any other activities: & 1 & \\
Games & & \\
\hline
\end{tabular}

6. Which statement best describes why you do the activities you chose in question 5?

\begin{tabular}{lcc}
\hline & Response total & Response Percent \\
\hline Because they are fun & 26 & $25 \%$ \\
Because I have a lot of free time & 6 & $6 \%$ \\
Because they will help me improve my English & 63 & $61 \%$ \\
\hline
\end{tabular}


Because my friends/family do them

3 $3 \%$

Other: Write down any other reasons you have

- For fun and learn

- Because the main language in most of the places is English!!

- $\quad$ Because it's part of my life

- $\quad$ Because I have to use the English in my daily life and it help me improve

- $\quad$ Because it is help me to learn more and for fun

- Because I speak English since I was little

- Because $i$ tend to like movies, songs, stories etc more. moreover, English is everywhere so you NEED to learn English or you are not going to make it to anywhere. Schools, universities, malls, they use english everywhere so it's very important to learn english.

7. Which of the following activities do you do out-of-class to improve your English? You may choose more than one.

\begin{tabular}{lcc}
\hline & Response total & Response Percent \\
\hline Read books on developing specific skills (reading, & 38 & $39 \%$ \\
listening, writing etc.) & 44 & $45 \%$ \\
Read novels/short stories & 37 & $38 \%$ \\
Read magazines/newspapers & 39 & $40 \%$ \\
Use dictionaries (monolingual/bilingual/picture & 14 & $14 \%$ \\
dictionary) & 63 & $65 \%$ \\
Use the self-study materials in the LC & 50 & $52 \%$ \\
Do Blackboard activities/material & 44 & $45 \%$ \\
Do level specific vocabulary exercises & 55 & $57 \%$ \\
Complete grammar worksheets and exercises from & 14 & $14 \%$ \\
grammar books & 65 & $67 \%$ \\
Speak with friends & 26 & $27 \%$ \\
Speak with family members & 82 & $85 \%$ \\
Listen to songs & 56 & $58 \%$ \\
Listen to the radio & 60 & $62 \%$ \\
Watch TV/films & 18 & $41 \%$ \\
Chat on smartphone apps & 40 & $26 \%$ \\
Use the Internet & 25 & $22 \%$ \\
Write on social networking sites (Facebook, twitter & 21 & $19 \%$ \\
etc.) & 18 & $19 \%$ \\
Read graded readers & & \\
Use IELTS/TOEFL study books and CDs & & \\
Play language games in the LC (e.g. Scrabble) & & \\
Join student clubs & & \\
\hline
\end{tabular}




\begin{tabular}{lcc}
\hline Borrow books from LC & 12 & $12 \%$ \\
$\begin{array}{l}\text { Other: Write down other activities you do to } \\
\text { improve your English. }\end{array}$ & 0 & $0 \%$ \\
\hline
\end{tabular}

8. Which of the following statements best describes why you do the out-of-class activities you chose in question $7 ?$

\begin{tabular}{lcc}
\hline & Response total & Response Percent \\
\hline $\begin{array}{l}\text { Because my teacher tells me to/gives it to me as } \\
\text { homework }\end{array}$ & 14 & $15 \%$ \\
Because I need them to prepare for exams & 32 & $34 \%$ \\
Because my friends use them & $\mathbf{2}$ & $\mathbf{2 \%}$ \\
$\begin{array}{l}\text { Because the library/LEC staff advise me to use } \\
\text { them }\end{array}$ & $\mathbf{0}$ & $\mathbf{0 \%}$ \\
Because I can easily find /use these materials & 6 & $6 \%$ \\
I've used these materials before and found them & 3 & $3 \%$ \\
useful & & $31 \%$ \\
Because I know what my weaknesses are and I \\
want to improve them
\end{tabular}

9. How often do you do something outside class hours to improve your English?

\begin{tabular}{lcc}
\hline & Response total & Response Percent \\
\hline Everyday & 14 & $14 \%$ \\
Usually & 28 & $29 \%$ \\
Sometimes & 45 & $46 \%$ \\
Rarely & 8 & $8 \%$ \\
Never & 2 & $2 \%$ \\
\hline
\end{tabular}

10. How much time do you spend out of class doing things to improve your English?

\begin{tabular}{lcc}
\hline & Response total & Response Percent \\
\hline 2 hours and more a day & 16 & $16 \%$ \\
1 to 2 hours a day & 55 & $57 \%$ \\
Less than one hour a day & 12 & $12 \%$ \\
A few hours a week & 8 & $8 \%$ \\
A few hours a month & 1 & $1 \%$ \\
A few hours a term & 1 & $1 \%$ \\
\hline
\end{tabular}




\begin{tabular}{lll}
\hline I don't study out of class & 4 & $4 \%$
\end{tabular}

\section{Appendix B}

\section{Template for learner journal}

Think about the activities you did in English this week and fill in the table. Send this document to your teacher or to me (email address).

\begin{tabular}{l}
\hline Date \\
\hline What was the activity? \\
Why did you do this activity? \\
How did you feel while doing this activity? \\
Where did this activity take place? \\
Who was with you while doing this activity? \\
Would you recommend this activity to your \\
classmates/friends? Why/why not?
\end{tabular}

\section{Appendix C}

\section{Interview prompts}

- Student interests and hobbies

- Student interactions beyond the classroom

- Role of English in students' lives beyond the classroom

- Roles and responsibilities required of them beyond the classroom

- Activities students engage in out-of-class to facilitate language development

- Students' interactions with other individuals out-of-class

- Student perceptions of out-of-class language learning

- Possible difficulties/obstacles experienced by students regarding learning out-of-class

- A typical day for a student after classes are over.

- Personal recommendations on learning out-of-class

\section{Copyrights}

Copyright for this article is retained by the author(s), with first publication rights granted to the journal.

This is an open-access article distributed under the terms and conditions of the Creative Commons Attribution license (http://creativecommons.org/licenses/by/4.0/). 